\title{
Stimulatory Effects of a Novel Peptidyl Plant Growth Factor, Phytosulfokine - $\alpha$, on the Adventitious Bud Formation from Callus of Antirrhinum majus
}

\author{
Guangxiao YANG*, Shihua SHEN*, Toshihiro KOBAYASHI*, ${ }^{\dagger}$, Yoshikatsu MATSUBAYASHI** \\ Youji SAKAGAMI** and Hiroshi KAMADA* \\ * Institute of Biological Sciences, University of Tsukuba,Tsukuba, Ibaraki 305-8572, Japan \\ E-mail : \\ ** School of Agricultural Sciences, Nagoya University, Chikusa, Nagoya 464-01, Japan
}

Received 23 October 1998; accepted 15 March 1999

\begin{abstract}
Phytosulfokine $-\alpha$ (PSK $-\alpha$ ) is a novel plant peptidyl growth factor that was originally isolated from the conditioned medium of cultures of asparagus mesophyll cells and was shown to stimulate cell division. To date, however, there have been no reports on the effects of PSK- $\alpha$ on morphogenesis in higher plants. Therefore, in this study, we examined the effects of PSK- $\alpha$ on formation of adventitious buds from calli of Antirrhinum majus. The formation of adventitious buds was induced on hypocotylderived callus that had formed on solid Murashige and Skoog's (MS) medium containing $1.2 \mu \mathrm{M}$ naphthoxyacetic acid. Addition of PSK $-\alpha$ in this medium at $10^{-8}, 10^{-7}$ and $10^{-6} \mathrm{M}$ stimulated the formation of adventitious buds. No adventitious buds developed from callus that had been cultured on MS medium containing 1.1 $\mu$ M 2,4-D with or without PSK- $\alpha$. However, when such callus was transferred to phytohormone- free MS medium that contained PSK- $\alpha$, as many as $10 \%$ of calli formed adventitious buds. The results indicate that PSK- $\alpha$ could stimulate organogenesis in higher plant.
\end{abstract}

\section{Introduction}

When plant cells are cultured at a low cell density, they do not divide in response to any known combination of phytohormones. However, cell division can be induced by the addition of conditioned medium (Stuart and Street, 1969) or by inclusion of a nurse culture (Blakely and Steward, 1964; Muir et al., 1954). It seems probable that some chemical factor(s) is secreted by cultured cells into the medium and this factor(s) stimulates cell division. Recently, two peptidyl compounds with mitogenic activity were isolated from the conditioned medium of cultures of Asparagus officinalis cells. Analysis of their chemical structures revealed that one was a sulfated pentapeptide and another was a sulfated tetrapeptide, and they were named as phytosulfokine - $\alpha$ [PSK - $\alpha ; \mathrm{H}-\operatorname{Tyr}\left(\mathrm{SO}_{3} \mathrm{H}\right)-\mathrm{Ile}-$ $\left.\operatorname{Tyr}\left(\mathrm{SO}_{3} \mathrm{H}\right)-\mathrm{Thr}-\mathrm{Gln}-\mathrm{OH}\right]$ and phytosulfokine $-\beta$ [PSK - $\beta ; \mathrm{H}-\mathrm{Tyr}\left(\mathrm{SO}_{3} \mathrm{H}\right)-\mathrm{Ile}-\mathrm{Tyr}\left(\mathrm{SO}_{3} \mathrm{H}\right)-\mathrm{Thr}-$ $\mathrm{OH}$, respectively (Matsubayashi and Sakagami, 1996). It was also demonstrated that both the amino-terminal sulfated tyrosine residue and the pres-

\footnotetext{
${ }^{\dagger}$ To whom correspondence should be addressed.
}

ence of sulfate residues at tyrosine residues 1 and 3 are necessary for activity since (2-5)PSK - $\alpha$ [H-Ile - Tyr $\left.\left(\mathrm{SO}_{3} \mathrm{H}\right)-\mathrm{Thr}-\mathrm{Gln}-\mathrm{OH}\right]$, non-sulfated PSK - $\alpha$ [H - Tyr - Ile - Tyr - Thr - Gln- OH], tyrosine sulfate[Tyr $\left.\left(\mathrm{SO}_{3} \mathrm{H}\right)\right]$ and certain other analogs of PSK failed to induce cell proliferation in cultures of asparagus cells (Matsubayashi et al., 1996). PSKs are the first endogenous peptidyl growth factors from higher plants to be chemically characterized and PSKs have been formed in cultures of tissues from various monocotyledonous and dicotyledonous plant species (Morita et al., 1998). However, to date, no information has been reported about the effects of PSKs on plant morphogenesis in tissue culture and their physiological roles remain to be determined.

As the first step towards clarification of the physiological roles of PSKs, we are performing experiments in tissue culture using various plant materials. In this report, we describe the effects of PSK $-\alpha$ on the formation of adventitious buds of Antirrhinum majus.

\section{Materials and Methods}

Seeds of Antirrhinum majus cv. Orchard, cv. White and cv. Rose were surface sterilized by a 
brief rinse in $70 \%(\mathrm{v} / \mathrm{v})$ ethanol and then in a $20 \%$ $(\mathrm{v} / \mathrm{v})$ solution of sodium hypochlorite ( final concentration of available chlorine, $1 \%$ ) for $10 \mathrm{~min}$. After sterilization, the seeds were washed five times with sterile distilled water. They were placed in a $300 \mathrm{ml}$ flask that contained $100 \mathrm{ml}$ of semi-soli dified ( $0.7 \%$ agar) phytohormone - free half-strength Murashige and Skoog's medium (1/2MS) (Murashige and Skoog, 1962) with $1 \%$ sucrose and incubated in a growth chamber at $25{ }^{\circ} \mathrm{C}$ with a $16-\mathrm{h}$ photoperiod and illumination with light at $50 \mu$ moles $\cdot \mathrm{m}^{-2} \cdot \mathrm{s}^{-1}$.

Hypocotyls of 21-day-old seedlings were cut into $0.5-\mathrm{cm}$ segments. Five segments were placed in a $90-\mathrm{mm}$ Petri-dish that contained semi-solidified $(0.7 \%$ agar) MS medium with $3 \%$ sucrose plus $1.2 \mu \mathrm{M}$ naphthoxyacetic acid (NOA) or $1.1 \mu$ M 2,4-D. Solutions of PSK - $\alpha$, (2,5)PSK - $\alpha$ and $\operatorname{Tyr}\left(\mathrm{SO}_{3} \mathrm{H}\right)$ prepared as described elsewhere (Matsubayashi and Sakagami, 1996), were sterilized by filtration and added to the medium at a final concentration of $10^{-8}, 10^{-7}$ or $10^{-6} \mathrm{M}$. The dishes were sealed with Parafilm ${ }^{\mathrm{TM}}$ and incubated under the conditions described above. The percentage of explants that produced calli, the percentage of calli that produced adventitious buds, and the average numbers of adventitious buds on each callus were recorded after the indicated times. Fifteen segments were used for each treatment and experiments were repeated twice with seeds of cv. White and cv. Rose and at least four times with seeds of cv. Orchard.

\section{Results}

When hypocotyl explants were cultured on MS medium that contained $1.2 \mu \mathrm{M}$ NOA, calli formed on the explants of all three cultivars within 14 days. After 30 days in culture on medium without PSK$\alpha$, adventitious buds were recognized on the calli of cv. Orchard and cv. Rose but not on calli of cv. White. The frequency of formation of buds was $29 \%$ in cv. Orchard and $4 \%$ in cv. Rose (Table 1). Addition of PSK $-\alpha$ at $10^{-6} \mathrm{M}$ to the medium increased this frequency to $43 \%$ in cv. Orchard and $21 \%$ in cv. Rose. While calli of cv. White failed to produce adventitious buds on MS medium without PSK - $\alpha$, as many as $27 \%$ of calli produced adventitious buds by the addition of PSK - $\alpha$. The stimulatory effect of PSK - $\alpha$ was also observed in cv. Rose and cv. White when we examined the average number of adventitious buds produced per callus (Table 1). By contrast, when hypocotyl explants were cultured on MS medium that contained both $1.2 \mu \mathrm{M}$ NOA and $4.4 \mu \mathrm{M} \mathrm{BA}$, explants of all three

Table 1. Effects of PSK - $\alpha$ on the formation of adventitious buds of Antirrhinum majus in MS medium that contained naphthoxyactic acid (NOA).

\begin{tabular}{ccccc}
\hline Cultivar & $\begin{array}{c}\text { Conc. of } \\
\text { PSK }-\alpha(\mathrm{M})\end{array}$ & $\begin{array}{c}\text { \% of explant } \\
\text { producing callus }\end{array}$ & $\begin{array}{c}\text { \% of callus } \\
\text { producing buds }\end{array}$ & $\begin{array}{c}\text { Average no. of } \\
\text { buds per callus }\end{array}$ \\
\hline \multirow{6}{*}{ Orchard } & 0 & 100 & $29.0 \pm 0.5$ & $0.63 \pm 0.18$ \\
& $10^{-8}$ & 100 & $33.3 \pm 1.5$ & $0.62 \pm 0.20$ \\
& $10^{-7}$ & 100 & $40.9 \pm 1.2$ & $0.85 \pm 0.21$ \\
& $10^{-6}$ & 100 & $42.8 \pm 0.6$ & $0.67 \pm 0.15$ \\
& $\mathrm{NB}^{*}$ & 100 & $15.0 \pm 1.1$ & $0.25 \pm 0.10$ \\
\hline \multirow{6}{*}{ White } & 0 & 100 & $0.0 \pm 0.0$ & $0.00 \pm 0.00$ \\
& $10^{-8}$ & 100 & $16.0 \pm 1.4$ & $0.24 \pm 0.10$ \\
& $10^{-7}$ & 100 & $26.9 \pm 1.5$ & $0.42 \pm 0.18$ \\
& $10^{-6}$ & 100 & $9.1 \pm 0.1$ & $0.38 \pm 0.09$ \\
Rose & $\mathrm{NB}^{*}$ & 100 & $15.4 \pm 1.2$ & $0.15 \pm 0.05$ \\
\hline & 0 & 100 & $4.0 \pm 0.6$ & $0.04 \pm 0.02$ \\
& $10^{-6}$ & 100 & $20.8 \pm 1.8$ & $0.33 \pm 0.10$ \\
& $\mathrm{NB}^{*}$ & 100 & $13.4 \pm 1.2$ & $0.27 \pm 0.09$ \\
\hline
\end{tabular}

Hypocotyl explants were cultured on MS medium that contained $1.2 \mu \mathrm{M}$ NOA with or without PSK $-\alpha$. After two weeks of culture, calli were formed.

Formation of adventitious buds was examined after one month in culture. Values represent means \pm SD of results from two replicates for each treatment in case of $\mathrm{cv}$. White and cv.Rose and from four replicates in case of cv.Orchard.

${ }^{*}$ MS medium that contained $1.2 \mu \mathrm{M}$ NOA and $4.4 \mu \mathrm{M}$ BA. 
cultivars formed calli and then produced adventitious buds, but the frequencies were lower than those on MS medium that contained NOA and PSK $-\alpha$ both on the basis of percentages of calli that produced adventitious buds and the average numbers of adventitious buds produced per callus ( Table 1).

Calli also developed from hypocotyl explants of cv. Orchard that were cultured on MS medium containing $1.1 \mu \mathrm{M} 2,4-\mathrm{D}$. The growth rates of these calli were much lower than those of calli that developed on the medium containing $1.2 \mu \mathrm{M}$ NOA. When calli were cultured continuously on $2,4-\mathrm{D}$ containing medium, no adventitious buds were detected on the calli after 45 days of culture, even when PSK - $\alpha$ was included in the medium. When these calli were transferred to phytohormone-free medium that contained $10^{-7} \mathrm{M}$ PSK - $\alpha$, as many as $10 \%$ of the calli had formed adventitious buds within 15 days of the transfer (Table 2). By contrast, no adventitious buds were observed on control calli cultured without PSK $-\alpha$. Moreover, treatments with tyrosine sulfate and with $(2,5)$ PSK - $\alpha$, which had been used previously as negative control chemicals (Matsubayashi et al., 1996), had no effect on the formation of adventitious buds (Table 2).

\section{Discussion}

There are several reports of successful regeneration of plants from callus cultures of $A$. majus (Atkinson et al., 1989; Pfister and Widholm, 1984; Sangwan and Harada, 1975). However, regenerative ability differed considerably among the various types of explant and among cultivars tested. The most reliable procedure for regeneration of plants from hypocotyl-derived callus appears to require MS medium that contained $1.2 \mu \mathrm{M}$ NOA and $10 \%$ (v/v) coconut milk (Atkinson et al., 1989). In our experiments, adventitious buds formed on callus of two out of three tested cultivars when calli were cultured on MS medium that contained $1.2 \mu \mathrm{M}$ NOA alone. However, the frequency of regeneration was relatively low. Addition of PSK - $\alpha$ to NOAcontaining medium clearly enhanced the formation of adventitious buds.

In the case of cv. Orchard, no adventitious buds developed on calli grown on MS medium that contained 1.1 $\mu$ M 2,4-D even when PSK - $\alpha$ was added to the medium. When such calli were transferred to phytohormone-free MS medium that contained PSK - $\alpha$, as many as $10 \%$ of calli formed adventitious buds. After growth of calli on 2,4-Dcontaining MS medium without PSK - $\alpha$, no adven-

Table 2. Effects of PSK - $\alpha$ and two analogs on the formation of adventitious buds from calli of Antirrhinum majus cv.Orchard induced on 2,4-Dcontaining MS medium.

\begin{tabular}{lccc}
\hline Chemicals & Concentration (M) & $\begin{array}{c}\text { \% of callus } \\
\text { producing buds }\end{array}$ & $\begin{array}{c}\text { Average no. of } \\
\text { buds per callus }\end{array}$ \\
\hline & 0 & $0.0 \pm 0.0$ & $0.00 \pm 0.00$ \\
PSK- $\alpha$ & $10^{-8}$ & $6.3 \pm 0.9$ & $0.15 \pm 0.05$ \\
& $10^{-7}$ & $10.0 \pm 1.4$ & $0.22 \pm 0.08$ \\
& $10^{-6}$ & $9.3 \pm 1.5$ & $0.17 \pm 0.11$ \\
\hline & 0 & 0.0 & 0.00 \\
$(2,5)$ PSK- $\alpha$ & $10^{-8}$ & 0.0 & 0.00 \\
& $10^{-7}$ & 0.0 & 0.00 \\
& $10^{-6}$ & 0.0 & 0.00 \\
\hline & 0 & 0.0 & 0.00 \\
Tyr- $\mathrm{SO}_{3} \mathrm{H}$ & $10^{-8}$ & 0.0 & 0.00 \\
& $10^{-7}$ & 0.0 & 0.00 \\
& $10^{-6}$ & 0.0 & 0.00 \\
\hline
\end{tabular}

Calli that had formed on 2,4-D- containing MS medium supplemented with PSK $-\alpha,(2,5) \mathrm{PSK}-\alpha$ or $\mathrm{Tyr}-\mathrm{SO}_{3} \mathrm{H}$ were transferred to phytohormore-free MS medium that contained the same concentrations of PSK $-\alpha,(2,5) \mathrm{PSK}-\alpha$ or $\mathrm{Tyr}-\mathrm{SO}_{3} \mathrm{H}$, respectively. The formation of adventitious buds were examined 15 days after transfer. Values represent means \pm SD of three replicantes. 
titious buds developed on the calli even after they had been transferred to phytohormone-free MS medium.

PSKs were first isolated from conditioned medium obtained from cultures of asparagus mesophyll cells as growth factors that stimulated cell proliferation, and they appear to be dominant conditioning factors. They have since been identified in the conditioned media from cell cultures of plants such as rice (Matsubayashi et al., 1997), carrot (Hanai et al., 1998 ) and zinnia (Morita et al., 1998), having stimulatory effects on colony formation by rice protoplasts (Matsubayashi et al., 1997), on somatic embryogenesis in carrot (Kobayashi et al., 1998), and on tracheary element differentiation in zinnia (Matsubayashi et al., 1998). In this report, we demonstrated that PSK $-\alpha$ stimulates the formation of adventitious buds on calli derived from hypocotyl segments of $A$. majus. These results together suggest that PSKs might exist in all higher plants and act to stimulate cell proliferation and some aspects of morphogenesis. Recently, it was reported that another plant peptide, ENOD 40 stimulates cell division and functions in the formation of nodules upon infection by Rhizobium (Charon et al., 1997). PSKs and ENOD 40 might be representative of a novel class of endogenous plant growth factors. Further analysis of their physiological functions should provide new insight into mechanisms that control the growth and differentiation of higher plants.

\section{Acknowledgement}

This work was supported in part by the Program for Promotion of Basic Research Activities for Innovative Biosciences from Bio-oriented Technology Research Advancement Institution.

\section{References}

Atkinson, N., Ford-Lloyd, B.V., Newbury, H.J., 1989. Regeneration of plants from Antirrhinum majus L. callus. Plant Cell Tiss. Org. Cult., 17: 59-71.

Blakely, L.M., Steward, F.C., 1964. Growth and organized development of cultured cell. VI. The behavior of individual cells on nutrient agar. Am.J.Bot., 51: 792807.

Charon, C., Johansson, C., Kondorosi, E., Kondorosi, A., Crespi, M., 1997. ENOD 40 induces dedifferentiation and division of root cortical cells in legumes. Proc. Natl. Acad. Sci. USA., 94: 8901-8906.
Hanai, H., Matsuno,T., Kobayashi, T., Kamada, H., Sakagami, Y., 1998. Phytosulfokine stimulates the development of carrot somatic embryo. Abstract of the 16th International Conference on Plant Growth Substances, Makuhari, Messe, Chiba, Japan, p.100.

Kobayashi, T., Eun, C., Higashi, K., Hanai, H., Matsubayashi, Y., Sakagami, Y., Kamada, H., 1998. Phytosulfokine $-\alpha$, a peptidyl plant growth factor, stimulates cell division and somatic embryogenesis in carrot. Abstract of the 16th International Conference on Plant Growth Substances, Makuhari, Messe, Chiba, Japan, p.101.

Matsubayashi,Y., Omura, N., Takagi, L., Sakagami, Y., 1998. A sulfated pentapeptide, Phytosulfokine $-\alpha$, stimulates tracheary element differentiation as well as cell proliferation. Abstract of the 16th International Conference on Plant Growth Substances, Makuhari, Messe, Chiba, Japan, p.100.

Matsubayashi, Y., Takagi, L., Sakagami, Y., 1997. Phytosulfokine - $\alpha$, a sulfated pentapeptide, stimulates the proliferation of rice cell by means of specific high - and low - affinity binding sites. Proc. Natl. Acad. Sci. USA., 94: 13357-13362.

Matsubayashi,Y., Hanai, H., Hara, O., Sakagami, Y., 1996. Active fragments and analogs of the plant growth factor, phytosulfokine: structure-activity relationships. Biochem. Biophys. Res. Commun., 255: 209-214 .

Matsubayashi,Y., Sakagami, Y.,1996. Phytosulfokine, sulfated peptides that induce the proliferation of single mesophyll cell of Asparagus officinalis L. Proc. Natl. Acad. Sci. USA., 93: 7623-7627 .

Morita, A., Matsunaga, E., Matsubayashi, Y., Kamada, H., Sakagami, Y., 1998. A sulfated pentapeptide, phytosulfokine $-\alpha$, universally distributed in plant kingdom. Abstract of the 16th International Conference on Plant Growth Substances, Makuhari, Messe, Chiba, Japan, p.100.

Muir, W.H., Hildebrandt, A.C., Riker, A.J., 1954. Plant tissue cultures from single isolated plant cell. Science, 119: $877-878$.

Murashige, T., Skoog ,F., 1962. A revised medium for rapid growth and bioassays with tobacco tissue cultures. Physiol. Plant., 15: 473- 497.

Pfister, J.M., Widholm, J.M., 1984. Plant regeneration from snapdragon tissue cultures. HortScience, 19: 852-854.

Sangwan, R.S., Harada, H ., 1975. Chemical regulation of callus growth, organogenesis, plant regeneration and somatic embryogenesis in Antirrhinum majus tissue and cell culture. J. Exp. Bot., 26: 868-881.

Stuart, R., Street, H.E., 1969. Studies on the growth in culture of plant cell. IV. The initiation of division in suspension of stationary phase cell of Acer pseudoplantanus L.. J. Exp. Bot., 20: 556-571. 